\title{
In Situ and Laboratory Microalgal Assays in the Tropics: A Microcosm Simulation of Edge-of-Field Pesticide Runoff
}

\author{
M. Moreira-Santos, ${ }^{1}$ E. M. da Silva, ${ }^{2}$ A. M. V. M. Soares, ${ }^{3}$ R. Ribeiro ${ }^{1}$ \\ 1 Departamento de Zoologia, Universidade de Coimbra, Largo Marquês de Pombal, \\ 3004-517 Coimbra, Portugal \\ 2 Instituto de Biologia da UFBa, Campus Universitário, CEP 40110-170 Salvador, \\ BA, Brazil \\ 3 Departamento de Biologia da Universidade de Aveiro, Campus Universitário de \\ Santiago, 3810-193 Aveiro, Portugal
}

Received: 15 July 2004/Accepted: 24 September 2004

At present, there is a general consensus on the scarcity of available toxicity tools to perform environmentally relevant assessments in tropical and subtropical regions (Lacher and Goldstein 1997). The vast majority of toxicity assays developed over the past decades in Europe and North America may not be directly applied to the tropics, due to the large differences in species sensitivity as well as in the physical, chemical and biological processes between temperate and tropical environments (Lacher and Goldstein 1997). Also, major environmental problems in the tropics differ from those encountered in temperate regions (Lacher and Goldstein 1997). For example, large-scale agricultural activities in the tropics are often times responsible for the contamination of surface waters by pesticides, through spray drift or edge-of-field runoff (Lahr et al. 2000). Although laboratory single-species toxicity assays are generally used to evaluate the potential hazard of contaminants to aquatic ecosystems, in situ assays are more ecologically relevant because they integrate much of the natural fluctuating conditions with a minimum of manipulations (Chappie and Burton 2000; Moreira-Santos et al. 2004). They also facilitate the use of local species as they are adapted already to the local conditions and do not need to be subjected to acclimation and transportation stress, increasing ecological relevance and reducing the risks of introducing nonindigenous species (Chappie and Burton 2000). Furthermore, the recognition that each toxicity tool has its own value has led to the emergence of integrative toxicity studies that combine information generated by laboratory and in situ tools to more accurately assess ecosystem quality (Culp et al. 2000).

As part of a research project aimed at contributing to the development of toxicity tools to perform ecologically relevant assessments in subtropical/tropical aquatic systems, this study describes the work conducted for phytoplankton. Laboratory algal assays have been established and are routinely employed to assess the impacts of contaminants on ecosystems (OECD 1984; USEPA 1994), while algal in situ assays have been less investigated and their implementation is still limited (Moreira-Santos et al. 2004). The immobilization of algae in an alginate matrix solves problems related with cell handling and recovery at the end of the assay, and with cell loss during testing by sedimentation, grazing, water flow or biofouling (Moreira dos Santos et al. 2002). The algal species selected for these assays are usually chosen for their availability, reproducible growth under 
laboratory conditions and reliable toxicity responses. Yet, the environmental relevance of algal assays would be enhanced by using species or even the phytoplankton community occurring in the natural ecosystem. The main objective of this study was to evaluate laboratory (single-species and local phytoplankton community) and in situ (local community) microalgal growth assays under a realistic simulation of surface water contamination by a runoff-related pesticide input in a tropical region.

\section{MATERIALS AND METHODS}

To evaluate the proposed assays and compare the in situ and laboratory responses under a realistic exposure scenario of surface water contamination, a runoff event simulating heavy rainfall was provoked over an agricultural field (Cruz das Almas, Bahia, Brazil: $12^{\circ} 38^{\prime} 23^{\prime \prime} \mathrm{S}, 39^{\circ} 52^{\prime} 13^{\prime \prime} \mathrm{W}$ ) after the application of the pesticide deltamethrin. Three $30-\mathrm{m}^{2}$ strips of land were isolated in the study area. On two of the isolated strips of land deltamethrin was applied as Decis EC25 (emulsifiable concentrate at $25 \mathrm{~g}$ a.i./L) (Aventis CropScience, São Paulo, Brazil), at the recommended and 20 times the recommended application rate to control for the grasshopper Rhamatocerus conspersus in pasture cultures, i.e., $10 \mathrm{~g}$ a.i./ha, while the third strip of land served as the control. The highest application rate was intended to simulate a worst case scenario, as overuse of plant-protection products is frequent among local farmers. A runoff event was then provoked on each strip of land with water from a reference lagoon adjacent to the study area. To discriminate the effects of Decis from those of other potential stress factors, for each assay seven treatments (microcosms) were run. Each microcosm consisted of $20-\mathrm{L}$ containers filled with a $15-\mathrm{cm}$ layer of sediment $(3 \mathrm{~L})$ from the reference lagoon and 15-L of treatment water. The following microcosms were set up, immediately after collecting the runoff water: (1) microcosms with water from the reference lagoon $(\mathrm{R})$ to investigate the effect of microcosm design, (2) microcosms with 25 (RR25) and 75\% (RR75) of runoff water from the strip of land without Decis application plus 75 and $25 \%$ of reference water, respectively, to investigate the effect of runoff per se, and (3) microcosms with 25 and $75 \%$ of runoff water from the strips of land where the low (LR25 and LR75) and high rates of Decis were applied (HR25 and HR75), plus 75 and $25 \%$ of reference water, respectively, to assess the effect of deltamethrin. Six microcosms were set up per treatment, three to perform the in situ assay and three to collect water for the laboratory assays. They were sunk into the lagoon to avoid daily temperature fluctuations, and left to stabilize for $5 \mathrm{~d}$ prior to assay initiation. During the study, no deltamethrin analyses were performed because assuring an environmentally realistic concentration range of deltamethrin following agricultural runoff was considered sufficient to fulfill our main goal, i.e., evaluate the suitability of the proposed microalgal assays for subtropical/tropical regions.

The in situ and laboratory assays consisted of 72-hr growth tests conducted following guidelines for algal toxicity assays (OECD 1984). Whereas the in situ control consisted of deploying the assay chambers directly at the reference lagoon, outside the microcosms, the laboratory controls followed standard procedures (see 
below). Assays were performed with the microalgae immobilized in alginate gel beads prepared as described in Moreira-Santos et al. (2004). A single in situ assay was carried out with the phytoplankton community indigenous to the reference lagoon, while two laboratory assays were performed, one with the local phytoplankton and another with Pseudokirchneriella subcapitata (Koršhikov) Hindak (formerly known as Raphidocelis subcapitata Koršhikov and Selenastrum capricornutum Printz), a species of green algae widely used and recommended for toxicity testing (OECD 1984; USEPA 1994). The latter was obtained from the Carolina Biological Supply Company (Burlington, NC) and maintained in nonaxenic batch cultures, in Woods Hole MBL growth medium (Stein 1973) (MBL medium), at $20 \pm 1^{\circ} \mathrm{C}$, under continuous cool-white fluorescent light (100 $\mu \mathrm{E} / \mathrm{m}^{2} / \mathrm{s}$ ). Beads with $P$. subcapitata were made with an initial cell concentration of $10^{6}$ cells $/ \mathrm{mL}$ of alginate, a value known to be suitable for the growth of immobilized P. subcapitata (Moreira-Santos et al. 2004). The natural phytoplankton was collected from a depth of around $0.5 \mathrm{~m}$ at the day of bead preparation. Lagoon water was sequentially filtered through 50 and $10-\mu \mathrm{m}$ meshes (the first to remove large zooplankton). The filtrate kept on the smaller filter was stored at around $15^{\circ} \mathrm{C}$ in darkness and brought to the laboratory. It was left for sedimentation of larger particles for a few min, the supernatant was centrifuged, and the algal paste was resuspended in $\mathrm{MBL}$ medium and immediately immobilized at a concentration of $5 \times 10^{4}$ cells $/ \mathrm{mL}$ of alginate. This lower bead cell density, also reported as adequate for the growth of immobilized algae (Hertzberg and Jensen 1989), was chosen because the local phytoplankton was dominated by Chlorophyceae mostly represented by a species of a cell size approximately 20 times that of $P$. subcapitata. Growth during the assays was estimated as the mean specific growth rate per day (Nyholm and Källqvist 1989), based on fluorometric readings (Fluorometer 10-AU, Turner Designs, Sunnyvale, CA), which have shown good agreement $\left(r^{2}=95.0 \%, P<0.001\right)$ with cell densities of $10^{4}$ to $50 \times 10^{6}$ cells $/ \mathrm{mL}$. Readings were taken at the start and end of each assay from three replicates of 30 beads and from the groups of beads of each treatment, respectively, by dissolving the beads in $8 \mathrm{~mL}$ of a $6 \%(\mathrm{w} / \mathrm{v})$ trisodium citrate solution. An additional set of 30 blank beads (i.e., not inoculated with algae) was incubated for each treatment under exactly the same conditions.

The in situ assay was carried out using the apparatus previously developed for in situ assays with immobilized algae, designed to optimize simplicity at deployment and retrieval, light penetration, and water flow (Moreira-Santos et al. 2004). Briefly, it consisted of a chamber for bead exposure (CBE) and an outer chamber to avoid damage and reduce mesh fouling and particle flocculation within the CBE. Each CBE with cavities for bead exposure was formed by joining two acrylic plates with four holes covered on the outer side by a $64-\mu \mathrm{m}$ mesh. The outer chamber consisted of a 1.1-L white-translucent plastic box (Tupperware, A02, Abrantes, Portugal) with two side windows and the lid made of a $200-\mu \mathrm{m}$ mesh, and a plastic-coated electric wire structure fixed inside for positioning the $\mathrm{CBE}$ at the height of the windows. All materials were fixed with a nontoxic (Pereira et al. 1999) white-thermal glue (Elis-Taiwan, TN122/WS, Taiwan). Each treatment was deployed in triplicate, with one $\mathrm{CBE}$ and respective outer chamber 
per microcosm. An additional treatment (three replicates) was deployed directly at the lagoon to assess whether algal growth was nutrient limited. It consisted of adding a nutrient source (fertilizer particles: Blaukorn, 0008, Aventis CropScience, Lisboa, Portugal) to the outer chambers $(\mathrm{L}+\mathrm{N})$. Deployment and retrieval procedures were described in Moreira-Santos et al. (2004). In short, beads were transported to the field inside $50-\mathrm{mL}$ beakers filled with storage medium. At the field, one set of 30 blank beads and three sets of 30 inoculated beads were placed on the cavities of each $\mathrm{CBE}$, which were then filled with treatment water dispensed through the meshed holes with the help of a plastic pipette. Each CBE was put in place and the outer chamber was closed and submerged to become filled with $200-\mu \mathrm{m}$ filtered water. After the 72-hr exposure, beads were preserved in Lugol's solution and transported to the laboratory to estimate growth rates. At the start and end of the in situ assay, $\mathrm{pH}$ (Digi-Sense 5938-00 pH/mv/ORP meter, Cole-Parmer, Niles, IL), conductivity (HI 9033 conductivity meter, Hanna Instruments, Singapore), oxygen and temperature (WTW OXI 196, WTW, Weilheim, Germany) were measured in the lagoon and each microcosm. All parameters were within optimal levels and comparable across treatments; $\mathrm{pH}$, conductivity $(\mu \mathrm{S} / \mathrm{cm})$, oxygen $(\%)$ and temperature $\left({ }^{\circ} \mathrm{C}\right)$ ranged between $6.70-8.34$, 174-206, 60-94, and 25.5-27.5, respectively.

Laboratory assays were conducted on all waters assessed in situ, except that of treatment $\mathrm{L}+\mathrm{N}$. Water samples were collected on the day of assay initiation and filtered through a $64-\mu \mathrm{m}$ mesh before testing. MBL medium was used as the standard control. The $P$. subcapitata assay was performed using simultaneously plain treatment waters and treatment waters enriched with the same nutrients making up the MBL. This is a recommended approach for laboratory algal assays evaluating the hazard of natural samples (USEPA 1994) as a way to discriminate toxic effects from those due to nutrient limitation. Both assays were performed in $100-\mathrm{mL}$ glass vials filled with $50 \mathrm{~mL}$ of medium, covered with laboratory Parafilm (American National Can, Menasha, WI), perforated to reduce evaporation but allow gas exchange. Vials were incubated at $26 \pm 1^{\circ} \mathrm{C}$ under continuous cool-white fluorescent light $\left(60 \mu \mathrm{E} / \mathrm{m}^{2} / \mathrm{s}\right)$. After a $72-\mathrm{hr}$ exposure, growth rates were estimated as stated above.

Growth rates were analyzed for significant differences by nested ANOVAs, oneway ANOVAs or independent samples $t$ tests. Because the runoff per se was shown to significantly affect the growth of $P$. subcapitata in the nutrient-enriched RR75 treatment, this runoff effect was removed to the respective Decis dosed treatments (LR75 and HR75) by adding to each replicate a correction factor corresponding to the runoff-related depression of growth, calculated using the mean percentage of growth inhibition in the RR75 undosed treatment (43.2\%).

\section{RESULTS AND DISCUSSION}

For both the in situ and laboratory assays with the local phytoplankton community (Figure 1), no significant differences in growth were found for algae exposed in controls without $(\mathrm{L})$ and with a nutrient supplement (L+N/MBL) (in situ: $F_{1,4}=$ 


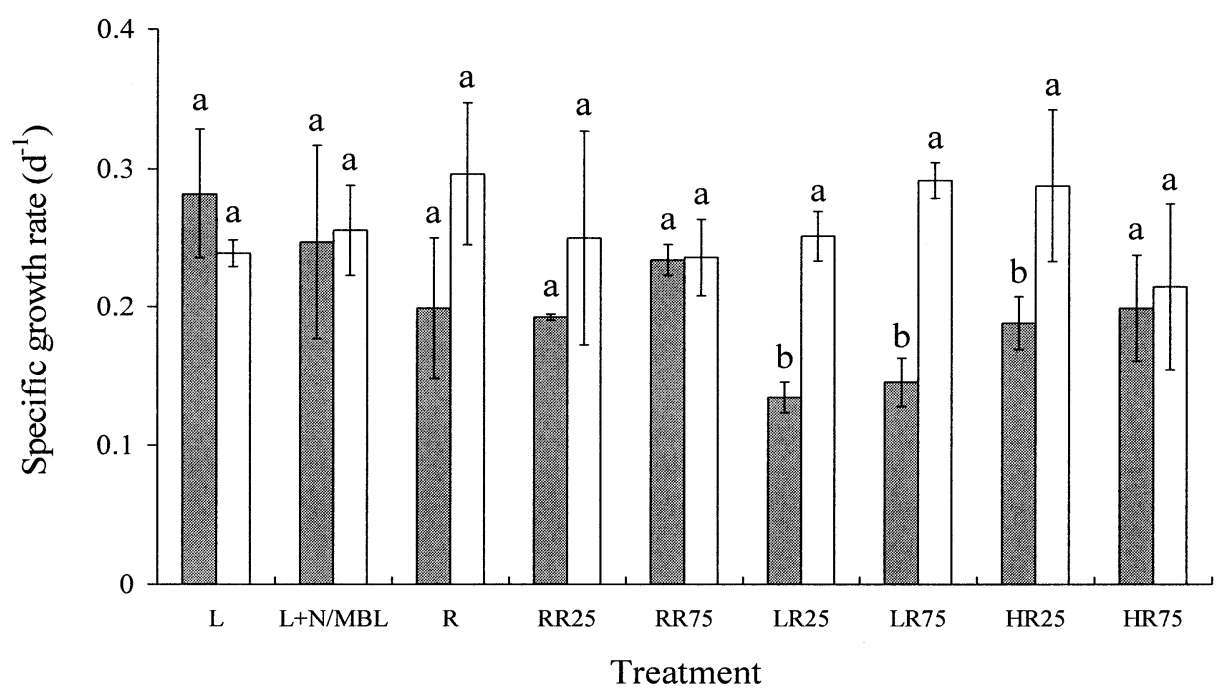

Figure 1. Mean 72-hr specific growth rates of the local phytoplankton community for the in situ (gray columns) and laboratory assay (white columns) Error bars indicate \pm 1 standard deviation; common letters above error bars indicate values not significantly different by independent samples $t$ tests within each treatment.

$0.53, P>0.25$; laboratory: $t_{4}=-0.85, P=0.45$ ). Also, comparable growth was found for the local phytoplankton deployed directly at the lagoon (L) or in the treatment simulating the lagoon (R) (in situ: $F_{1,4}=4.33, P>0.1$; laboratory: $t_{4}=$ $1.91, P=0.13$ ), and in treatment $\mathrm{R}$ or in those with runoff water from the control area (RR25 and RR75) (in situ: $F_{2,5}=1.25, P>0.25$; laboratory: $F_{2,6}=0.96, P=$ $0.44)$. Likewise, the growth of the local phytoplankton community was similar among treatment $\mathrm{R}$ and all four treatments with runoff water from the areas were Decis was applied (in situ: $F_{4,9}=2.23, P>0.05$; laboratory: $F_{4,10}=1.87, P=0.19$ ). Thus, the local phytoplankton growth was not affected by deltamethrin or any of the other stress factors considered here, namely nutrient limitation, microcosm design and runoff per se. However, the growth observed in the local phytoplankton community beads was rather poor, as the bead cell density increased by a maximum of a 2.5 -fold factor after the 72-hr exposure. The visual inspection of the beads at the end of the assays suggested that bead stability and integrity were maintained. The fact that adding nutrients to the reference water, either in the form of fertilizer $(\mathrm{L}+\mathrm{N})$ or according to a standard medium (MBL), did not enhance algal growth suggests that the growth of the local phytoplankton was limited by factors inherent to the beads. During the $P$. subcapitata assay, the bead cell density in the control (MBL) and nutrient-enriched L water increased by 26 and 33 times, respectively (not shown), corroborating the results of previous studies showing the good growth performance of $P$. subcapitata (Moreira-Santos et al. 2004). A plausible reason for this difference in growth between the local phytoplankton and $P$. subcapitata may be related with an excessive cell loading of the former beads, which restricted the diffusion of nutrients, carbon dioxide and light within the alginate matrix (Hertzberg and Jensen 1989; Moreira dos Santos et al. 2002). Also, 
the immobilization of the local phytoplankton cells in the beads may have induced a longer lag phase (Van Donk et al. 1993), which can be compensated for by increasing assay duration.

Figure 1 also shows that the growth of the local phytoplankton in the in situ and laboratory assays was similar for all $\left(t_{4}<2.33, P>0.05\right)$ except treatments LR25, LR75 and HR25 $\left(t_{3-4}>2.98, P<0.05\right)$. This difference between the in situ and laboratory growth of the local phytoplankton was probably due to the dissimilarities in the light regime conditions (light/dark cycle vs continuous light), which may not have been equally expressed for all treatments. Nonetheless, it appears that in general the in situ assay apparatus and procedures allowed comparable responses between the in situ and laboratory assays to be obtained, and was not responsible for the reduced growth of the local phytoplankton. Together with its inexpensive and simple design, allowing an easy deployment and the exposure of the algae to the continuously changing environmental conditions, the proposed assay includes an approach for discriminating nutrient limitation effects (occurring in most aquatic systems) from contaminant effects, by deploying chambers with an additional nutrient source.

For the laboratory assay with $P$. subcapitata (Figure 2), control growth (MBL: 1.1 $\mathrm{d}^{-1}$ ) was according to that found in previous studies for immobilized cells of this species (Moreira-Santos et al. 2004). As to the growth responses obtained with plain treatment waters, results confirmed those from the assays with the local phytoplankton, that neither the microcosm design ( $\mathrm{L}$ vs $\mathrm{R}: t_{4}=-0.77, P=0.48$ ) nor the runoff per se (R vs RR25 vs RR75: $F_{2,6}=2.14, P=0.20$ ) or deltamethrin (R vs LR25 vs LR75 vs HR25 vs HR75: $F_{4,10}=1.32, P=0.33$ ) had an effect on algal growth. Likewise, $P$. subcapitata growth in nutrient-enriched waters was not affected either by the microcosm design $\left(t_{4}=2.13, P=0.10\right)$ or deltamethrin $\left(F_{4,10}\right.$ $=1.91, P=0.18)$. However, a significant effect of the runoff per se on the growth of $P$. subcapitata was found with the nutrient-enriched treatment waters $\left(F_{2,6}=\right.$ 12.54, $P<0.01)$; growth in RR75 water was significantly lower than in $\mathrm{R}$ and RR25 waters. These results showed that turbidity, which was visually higher in treatments set up with runoff water than in those set up with water from the lagoon, was growth limiting at optimal nutrient levels. Surely, the presence of an elevated amount of suspended particles restricted light penetration, even though assay chambers were deployed at the water surface. Adding nutrients to the waters significantly increased $P$. subcapitata growth in all $\left(t_{4}<-3.27, P<0.02\right)$ but the RR75 treatment $\left(t_{4}=-0.094, P=0.93\right)$. Thus, it appears that nutrient limitation was the sole factor limiting algal growth in all treatments except in those prepared with the highest percentage of runoff water. The absence of an effect of the microcosm design on algal growth demonstrated that our simple and inexpensive microcosms were suitable to evaluate the proposed assays under an environmentally realistic scenario of surface water contamination. The use of such model ecosystems poses advantages over field studies because they allow a greater control of the experimental variables, and thus to maximize the information from the study (Culp et al. 2000). Although no deltamethrin analyses were performed throughout the assays, recent studies have shown the ecotoxicological relevance of 


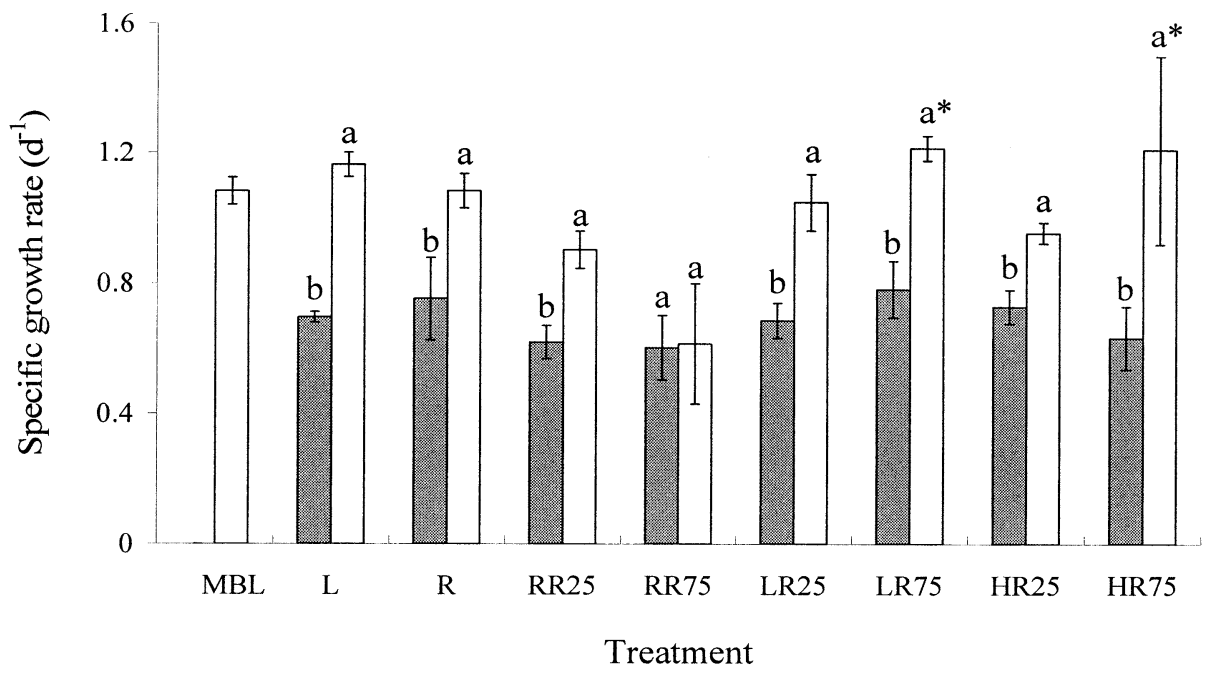

Figure 2. Mean 72-hr specific growth rates of Pseudokirchneriella subcapitata for the laboratory assay with plain (gray columns) and nutrient-enriched treatment waters (white columns). Error bars indicate \pm 1 standard deviation; $\left({ }^{*}\right)$ indicates values corrected to remove the effect of the runoff per se; common letters above error bars indicate values not significantly different by independent samples $t$ tests within each treatment.

pesticide residues (mainly particle-associated [hydrophobic] compounds like deltamethrin) occurring at environmentally realistic concentrations during edge-offield runoff events (Liess and Schulz 1999; Schulz and Liess 2001). The absence of toxic effects on microalgae growth observed in our study is in agreement with previous investigations showing that the direct toxicity of pyrethroid insecticides to algae is generally very low (DeLorenzo et al. 2001). Yet, changes in the phytoplankton community (abundance and composition) may occur as a result of direct toxic effects on the grazing pressure of the zooplankton community (DeLorenzo et al. 2001). Furthermore, because of their lipophilic nature, pyrethorids may accumulate in phytoplankton and be transferred to higher trophic levels, where they may exert toxic effects (DeLorenzo et al. 2001).

Acknowledgment. The work was partially funded by FCT (Portugal) (post-doctoral grant to first author) and the EU (TROCA-WET project, ref. ERBIC18-CT980264). Thanks also to Embrapa Cassava \& Fruits (Cruz das Almas, BA, Brazil) for technical and logistic assistance and to A Agra, A Barrreto, K Carvalho, L Cristina, L Guilhermino, I Lopes, A Kamei, S Moreira, J Paixão, J Rendón-von Osten, J Silva, A Soares, and C Stringuetti for laboratory and field assistance.

\section{REFERENCES}

Chappie DJ, Burton GA Jr (2000) Applications of aquatic and sediment toxicity testing in situ. Soil Sed Cont 9:219-245 
Culp JM, Lowell RB, Cash KJ (2000) Integrating mesocosm experiments with field and laboratory studies to generate weight-of-evidence risk assessments for large rivers. Environ Toxicol Chem 19:1167-1173

DeLorenzo ME, Scott GI, Ross PE (2001) Toxicity of pesticides to aquatic microorganisms: a review. Environ Toxicol Chem 20:84-98

Hertzberg S, Jensen A (1989) Studies of alginate-immobilised marine microalgae. Bot Mar 32:267-273

Lacher TE, Goldstein MI (1997) Tropical ecotoxicology: status and needs. Environ Toxicol Chem 16:100-111

Lahr J, Diallo AO, Gadji B, Diouf PS, Bedaux JJM, Badji A, Ndour KB, Andreasen JE, van Straalen NM (2000) Ecological effects of experimental insecticide applications on invertebrates in Sahelian temporary ponds. Environ Toxicol Chem 19:1278-1289

Liess M, Schulz R (1999) Linking insecticide contamination and population response in an agricultural stream. Environ Toxicol Chem 18:1948-1955

Moreira dos Santos M, Moreno-Garrido I, Gonçalves F, Soares AMVM, Ribeiro R (2002) An in situ bioassay for estuarine environments using the microalga Phaeodactylum tricornutum. Environ Toxicol Chem 21:567-574

Moreira-Santos M, Soares AMVM, Ribeiro R (2004) A phytoplankton growth assay for routine in situ environmental assessments. Environ Toxicol Chem 23:1549-1560

Nyholm N, Källqvist T (1989) Methods for growth inhibition toxicity tests with freshwater algae. Environ Toxicol Chem 8:689-703

OECD (1984) Algal growth inhibition test. OECD guidelines for testing of chemicals 201. Organisation for Economic Cooperation and Development, Paris

Pereira AMM, Soares AMVM, Gonçalves F, Ribeiro R (1999) Test chambers and procedures for in situ toxicity testing with zooplankton. Environ Toxicol Chem 18:1956-1964

Schulz R, Liess M (2001) Toxicity of aqueous-phase and suspended particleassociated fenvarelate: chronic effects after pulse-dosed exposure of Limnephilus lunatus (Trichoptera). Environ Toxicol Chem 20:185-190

Stein JR (1973) Handbook of phycological methods, culture methods, and growth measurements. Cambridge University Press, London

USEPA (1994) Short-term methods for estimating the chronic toxicity of effluents and receiving waters to freshwater organisms. EPA 600/7-91-002. United States Environmental Protection Agency, Washington, DC

Van Donk E, Faafeng BA, Hessen DO, Källqvist T (1993) Use of immobilized algae for estimating bioavailable phosphorus released by zooplankton. $\mathrm{J}$ Plankton Res 15:761-769 